\title{
uvby photometry of the mCP stars HD 35298, 19 Lyrae, HD 192678, and HR 8216
}

\author{
S.J. Adelman and R.H. Rice \\ Department of Physics, The Citadel, 171 Moultrie Street, Charleston SC 29409, U.S.A.
}

Received October 26; accepted December 12, 1998

\begin{abstract}
Differential Strömgren uvby observations from the Four College Automated Photoelectric Telescope are presented for the mCP stars HD 35298, 19 Lyr, HD 192678, and HR 8216. The period for HD 35298 of 1.85457 days is a revision of North's value while that for 19 Lyr of 7.0980 days is alias of that found by Winzer. HD 192678 is found to be a small amplitude photometric variable with the 6.4186 day period proposed by Leroy from polarization measurements. For HR 8216, observations taken between 1995 and 1998 confirm that the star has remained constant at least since 1990.
\end{abstract}

Key words: stars: individual: HD 35298; 19 Lyr, HD 192678; HR 8216 — stars: chemically peculiar

\section{Introduction}

This paper presents differential Strömgren uvby observations of four magnetic Chemically Peculiar (mCP) stars HD 35298, 19 Lyr, HD 192678, and HR 8216. Studies of the mCP stars using data from the Four College Automated Photoelectric Telescope (FCAPT) have both improved our knowledge of their rotational periods and better defined the shapes of their light curves (see, e.g. Adelman \& Brunhouse 1998 and references therein). These results can be used to better relate observations taken at different times and to study the period distribution of $\mathrm{mCP}$ stars. Their variable light curves provide information concerning the uniformity of the surface abundances. Hydrodynamical processes including diffusion and gravitational settling in radiative atmospheres with strong

Send offprint requests to: S.J. Adelman

* Tables 2, 3, 4 and 6 are only available in electronic form at the CDS via anonymous ftp to cdsarc.u-strasbg.fr (130.79.128.5) or via http://cdsweb.ustrasbg.fr/Abstract.html
Table 1. Photometric groups

\begin{tabular}{rllll}
\hline HD Number & Star Name & Type & $V$ & Spectral Type \\
\hline & & & & \\
35298 & & $v$ & 7.89 & B3VwHe \\
33647 & HR 1690 & $c$ & 6.67 & B9Vn \\
35640 & HR 1806 & $c h$ & 6.23 & B9.5Vn \\
& & & & \\
179527 & 19 Lyr & $v$ & 5.98 & B9pSi \\
181119 & HR 7324 & $c$ & 6.68 & A3V \\
180613 & & $c h$ & 6.79 & B9 \\
192678 & & & & \\
194668 & HR 7815 & $c$ & 6.51 & B9.5III \\
193592 & HR 7781 & $c h$ & 5.76 & A2Vs \\
& & & & \\
204411 & HR 8216 & $v$ & 5.13 & A6pCrEu: \\
205314 & HR 8246 & $c$ & 5.75 & A0V \\
203746 & & $c h$ & 6.84 & A1V \\
\hline
\end{tabular}

magnetic fields most likely produce the anomalous photospheric abundances of the $\mathrm{mCP}$ stars. Their abundance distributions are patchy and affect the emergent flux distribution. As their magnetic and rotational axes are not aligned, a distant observer will see photometric, magnetic, and spectrum variability as the stars rotate (Michaud \& Proffitt 1993 and references therein).

The FCAPT operated on Mt. Hopkins, AZ between September 1990 and July 1996 and since then on nearby Washington Camp, AZ. After the dark count, the tele-

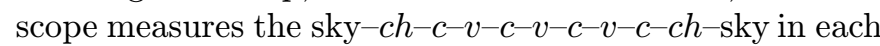
filter where sky is a reading of the sky, ch that of the check star, $c$ that of the comparison star, and $v$ that of the variable star. Table 1 contains group (a variable along with two supposedly non-variable stars, the comparison and check, against which the brightness of the variable is compared) information (Hoffleit 1982; Hoffleit et al. 1993). Corrections were not made for neutral density filter differences among the stars of each group. The comparison and check stars were chosen from supposedly non-variable stars in the vicinity of the variable on the sky that had 


\section{HD 35298}
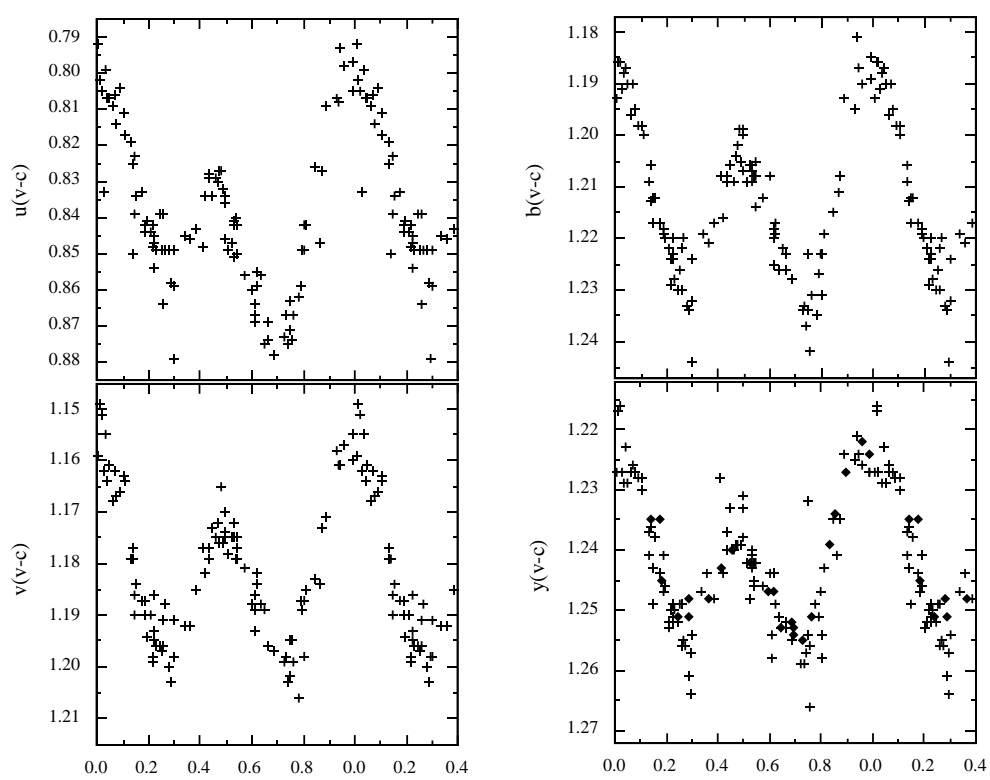

phase

Fig. 1. Photometry of HD 35298 plotted using this paper's ephemeris of HJD $\left(u_{\max }\right)=2444973.886+1.85457 E$. The FCAPT $u v b y$ values are indicated by + signs and North's $V$ magnitudes rezeroed to our $y$ magnitudes as closed diamonds

\section{Lyr}
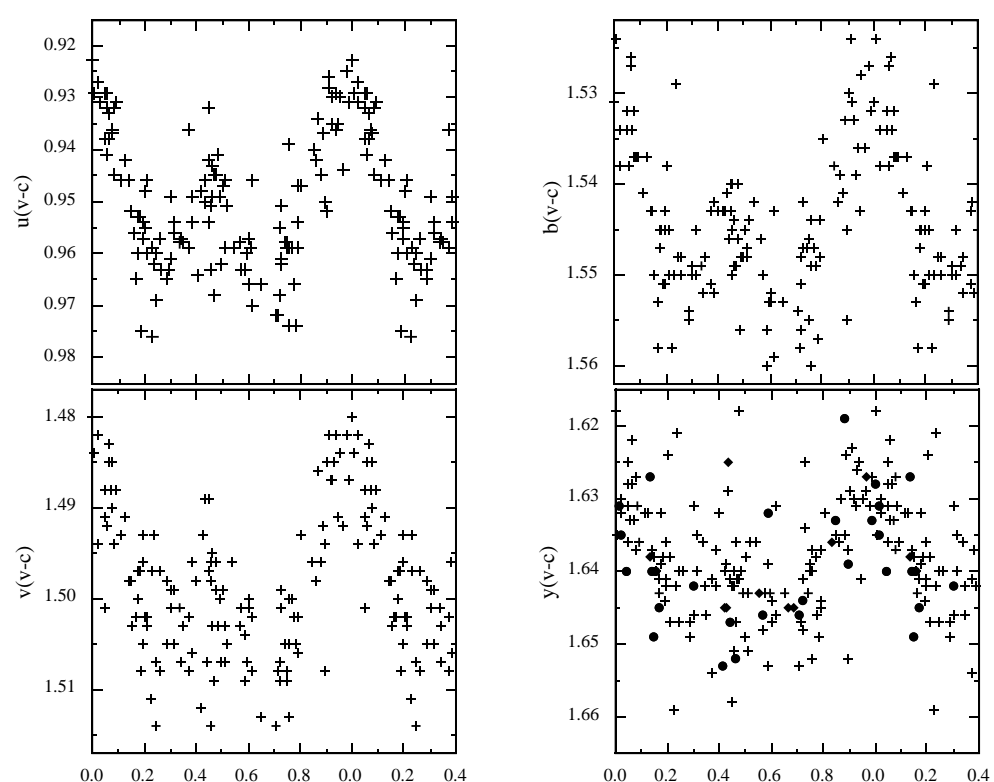

phase

Fig. 2. Photometry for 19 Lyr using the ephemeris HJD (light maximum) $=2441449.99+7.0980$ E. The FCAPT uvby values are indicated by + signs while the $V$ values of Winzer and Burke \& Barr rezeroed to the FCAPT $y$ scale are shown, respectively, as closed diamonds and circles 
Table 5. Summary of HR 8216's photometry

\begin{tabular}{|c|c|c|c|c|c|c|c|c|}
\hline $\begin{array}{l}\text { Heliocentric } \\
\text { Julian Date }\end{array}$ & $\begin{array}{c}u \\
v-c\end{array}$ & $\begin{array}{c}u \\
c h-c\end{array}$ & $\begin{array}{c}v \\
v-c\end{array}$ & $\begin{array}{c}v \\
c h-c\end{array}$ & $\begin{array}{c}b \\
v-c\end{array}$ & $\begin{array}{c}b \\
c h-c\end{array}$ & $\begin{array}{c}y \\
v-c\end{array}$ & $\begin{array}{c}y \\
c h-c\end{array}$ \\
\hline $\begin{array}{l}1990-91 \\
3 \text { values } \\
\text { average } \\
\text { std. dev. }\end{array}$ & $\begin{array}{l}0.013 \\
0.011\end{array}$ & $\begin{array}{l}1.106 \\
0.006\end{array}$ & $\begin{array}{r}-0.311 \\
0.009\end{array}$ & $\begin{array}{l}1.232 \\
0.005\end{array}$ & $\begin{array}{r}-0.416 \\
0.006\end{array}$ & $\begin{array}{l}1.276 \\
0.009\end{array}$ & $\begin{array}{r}-0.478 \\
0.003\end{array}$ & $\begin{array}{l}1.312 \\
0.005\end{array}$ \\
\hline $\begin{array}{l}1991-92 \\
24 \text { values } \\
\text { average } \\
\text { std. dev. }\end{array}$ & $\begin{array}{l}0.028 \\
0.003\end{array}$ & $\begin{array}{l}1.100 \\
0.005\end{array}$ & $\begin{array}{r}-0.296 \\
0.005\end{array}$ & $\begin{array}{l}1.227 \\
0.005\end{array}$ & $\begin{array}{r}-0.405 \\
0.004\end{array}$ & $\begin{array}{l}1.264 \\
0.004\end{array}$ & $\begin{array}{r}-0.463 \\
0.004\end{array}$ & $\begin{array}{l}1.302 \\
0.005\end{array}$ \\
\hline $\begin{array}{l}1992-93 \\
27 \text { values } \\
\text { average } \\
\text { std. dev. }\end{array}$ & $\begin{array}{l}0.026 \\
0.004\end{array}$ & $\begin{array}{l}1.105 \\
0.007\end{array}$ & $\begin{array}{r}-0.298 \\
0.003\end{array}$ & $\begin{array}{l}1.227 \\
0.005\end{array}$ & $\begin{array}{r}-0.405 \\
0.003\end{array}$ & $\begin{array}{l}1.265 \\
0.005\end{array}$ & $\begin{array}{r}-0.464 \\
0.003\end{array}$ & $\begin{array}{l}1.305 \\
0.006\end{array}$ \\
\hline $\begin{array}{l}1993-94 \\
13 \text { values } \\
\text { average } \\
\text { std. dev. }\end{array}$ & $\begin{array}{l}0.029 \\
0.005\end{array}$ & $\begin{array}{l}1.099 \\
0.009\end{array}$ & $\begin{array}{r}-0.296 \\
0.003\end{array}$ & $\begin{array}{l}1.224 \\
0.003\end{array}$ & $\begin{array}{r}-0.404 \\
0.002\end{array}$ & $\begin{array}{l}1.258 \\
0.004\end{array}$ & $\begin{array}{r}-0.464 \\
0.002\end{array}$ & $\begin{array}{l}1.303 \\
0.008\end{array}$ \\
\hline $\begin{array}{l}1994-95 \\
3 \text { values } \\
\text { average } \\
\text { std. dev. }\end{array}$ & $\begin{array}{l}0.028 \\
0.002\end{array}$ & $\begin{array}{l}1.103 \\
0.008\end{array}$ & $\begin{array}{r}-0.298 \\
0.003\end{array}$ & $\begin{array}{l}1.229 \\
0.002\end{array}$ & $\begin{array}{r}-0.405 \\
0.002\end{array}$ & $\begin{array}{l}1.257 \\
0.005\end{array}$ & $\begin{array}{r}-0.461 \\
0.002\end{array}$ & $\begin{array}{l}1.298 \\
0.007\end{array}$ \\
\hline $\begin{array}{l}1995-96 \\
4 \text { values } \\
\text { average } \\
\text { std. dev. }\end{array}$ & $\begin{array}{l}0.024 \\
0.004\end{array}$ & $\begin{array}{l}1.116 \\
0.011\end{array}$ & $\begin{array}{r}-0.299 \\
0.001\end{array}$ & $\begin{array}{l}1.267 \\
0.006\end{array}$ & $\begin{array}{r}-0.403 \\
0.002\end{array}$ & $\begin{array}{l}1.260 \\
0.004\end{array}$ & $\begin{array}{r}-0.461 \\
0.001\end{array}$ & $\begin{array}{l}1.308 \\
0.004\end{array}$ \\
\hline $\begin{array}{l}1996-97 \\
42 \text { values } \\
\text { average } \\
\text { std. dev. }\end{array}$ & $\begin{array}{l}0.032 \\
0.007\end{array}$ & $\begin{array}{l}1.133 \\
0.006\end{array}$ & $\begin{array}{r}-0.297 \\
0.007\end{array}$ & $\begin{array}{l}1.271 \\
0.005\end{array}$ & $\begin{array}{r}-0.412 \\
0.003\end{array}$ & $\begin{array}{l}1.267 \\
0.003\end{array}$ & $\begin{array}{r}-0.469 \\
0.004\end{array}$ & $\begin{array}{l}1.315 \\
0.005\end{array}$ \\
\hline $\begin{array}{l}1997-98 \\
59 \text { values } \\
\text { average } \\
\text { std. dev. }\end{array}$ & $\begin{array}{l}0.033 \\
0.005\end{array}$ & $\begin{array}{l}1.133 \\
0.008\end{array}$ & $\begin{array}{r}-0.298 \\
0.004\end{array}$ & $\begin{array}{l}1.274 \\
0.007\end{array}$ & $\begin{array}{r}-0.413 \\
0.003\end{array}$ & $\begin{array}{l}1.284 \\
0.007\end{array}$ & $\begin{array}{r}-0.468 \\
0.003\end{array}$ & $\begin{array}{l}1.315 \\
0.007\end{array}$ \\
\hline
\end{tabular}

similar $V$ magnitudes and $B-V$ colors. Adelman (1998) checked their stability using Hipparcos photometry (ESA 1997). We used the Scargle periodogram (Scargle 1982; Horne \& Baliunas 1986) and the clean algorithm (Roberts et al. 1987) in finding periods.

\section{HD 35298}

North (1984) derived a period of $1.85336 \pm 0.00116$ days for the Helium weak star HD 35298 (= V1156 Ori = BD $+1^{\circ} 996$ ), a member of the Ori OB1 association. This star exhibits a double-wave light curve with all colors varying in phase. The amplitude is as large as $0.07 \mathrm{mag}$ in the
Geneva photometric system. Borra (1981) measured the magnetic field with essentially this period.

We have 100 differential uvby observations, 56 from the $1995-96$ and 44 from the $1996-97$ observing seasons. A periodogram analysis resulted in a period close to one-half of North's period. But when we plotted the observations, there were two values for each phase indicating that the period was twice that. To have North's $V$ values properly rezeroed best overlay our $y$ values we had to adjust his period slightly. The zero epoch is better taken for maximum light in $u$. Thus

HJD $\left(u_{\max }\right)=2444973.886 \pm 0.006+(1.85457 \pm 0.00001)$ E. 


\section{HD 192678}
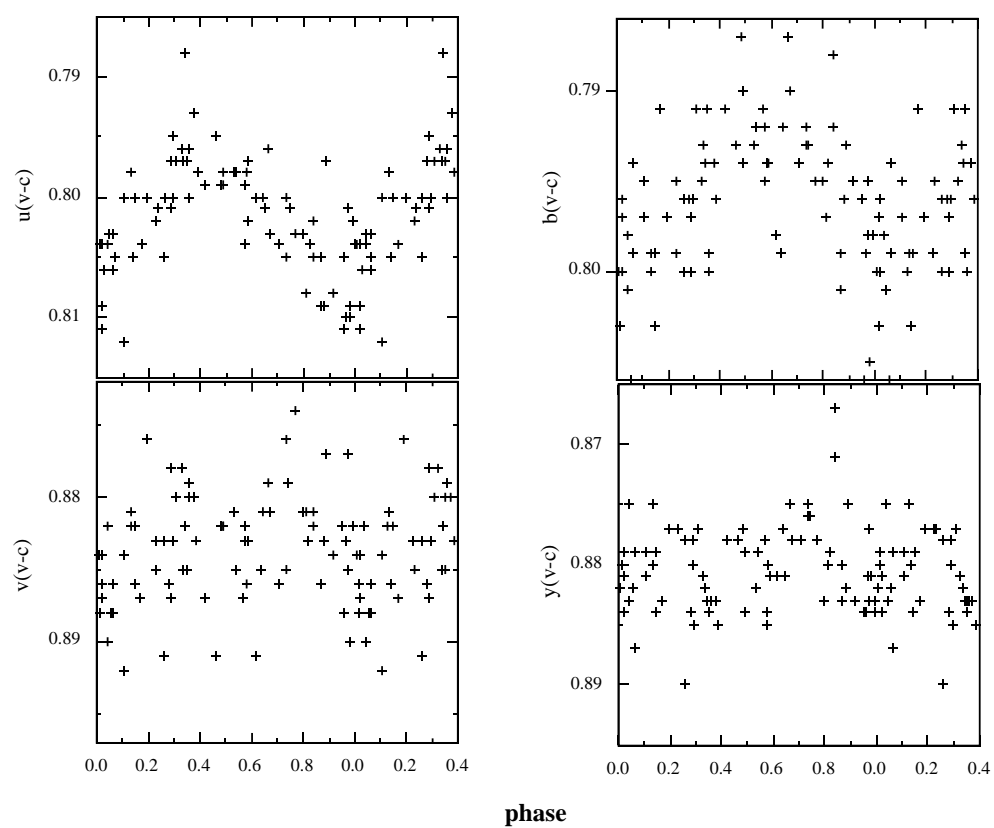

Fig. 3. Photometry of HD 192678 plotted with the ephemeris of Leroy (1995) JD (magnetic maximum) $=2444890.17+6.4186$ $E$. The FCAPT uvby values are indicated by + signs

Figure 1 shows our FCAPT photometry $(+$ signs $)$ and North's $V$ values (solid diamonds) on our $y$ magnitude scale plotted with our ephemeris. The amplitudes are $0.08 \mathrm{mag}$ for $u, 0.05 \mathrm{mag}$ for $v$ and $b$, and $0.037 \mathrm{mag}$ for $y$. The light curves are in phase with two minima and a primary and secondary maxima. Some light curves especially $u$ and $v$ show additional structure as the star begins the primary minimum. The relative depths of the two minima are more discrepant for $u$ than for $v, b$, and $y$. We are probably seeing most of the photosphere including both polar regions during the cycle. North's $U$ light curve has an amplitude similar to ours, but some of the details near phase 0.5 are not seen probably due to a lesser number of values. Likewise his $B$ light curve is similar to our $b$.

\section{19 Lyr}

Winzer (1974) discovered the light variations of 19 Lyr $(=$ HR $7283=$ HD $179527=$ V471 Lyrae $)$ of 0.04 mag in $U$ with smaller $B$ and $V$ amplitudes. His tentative period of 1.1608 days was based upon very limited data. Burke \& Barr (1981) obtained additional $U B V$ photometry and confirmed Winzer's period.

We obtained differential uvby observations of 19 Lyr: 18 in the 1995-96 observing season, 40 in 1996-97, and 66 in 1997-98. The periodogram contains several possible periods of which one near 7.10 days, which is an alias of Winzer's period, is the most likely and consistent with the $v \sin i$ value of Abt \& Morrell (1995), $20 \mathrm{~km} \mathrm{~s}^{-1}$. Using the $V$ data of Winzer and of Burke \& Barr, we refined the period. Winzer's zero epoch appeared to be satisfactory. Thus

HJD (light maximum) $=2441449.99 \pm 0.01+(7.0980$ $\pm 0.0001) E$.

Figure 2 shows the FCAPT values as + signs and Winzer's and Burke \& Barr's $V$ data rezeroed to our $y$ scale as solid diamonds and circles, respectively. The variations in $u, v$, $b$, and $y$ are in phase. The curves suggest possible incipient structure. The amplitudes are $0.045 \mathrm{mag}, 0.025 \mathrm{mag}$, $0.030 \mathrm{mag}$, and $0.025 \mathrm{mag}$ for $u, v, b$, and $y$, respectively. There is a sharp primary maximum with a weaker secondary maximum whose prominence decreases with increasing wavelength. Two approximately equal strength minima are symmetrically located with respect to the secondary maximum.

\section{HD 192678}

Leroy (1995) found the time variations of the Stokes parameters of HD 192678 (= V1372 Cyg $\left.=\mathrm{BD}+53^{\circ} 2368\right)$ could be described as

JD $($ magnetic maximum $)=2444890.17+6.4186 E$.

Mathys \& Lanz (1992) demonstrated that the determination of its period by Stepien (1968) of order 18 days was incorrect. Wade et al. (1996) presented a magnetic model consisting of an oblique rotating dipole with modified field line inclinations. The dipole has $\iota=173^{\circ}$ and $\beta=$ $120^{\circ}$. Their ephemeris uses the same period, but a slightly different zero point. Essentially the surface magnetic field is strongest near phase 0.00 and weakest near phase 0.50 . 
We obtained 77 differential uvby observations of HD 192678, 45 during the 1995-96 and 32 during the 199697 observing season (Table 4). As our analyses revealed a period close to that of Leroy's, we adopted his ephemeris and found that it was adequate to describe our observations. To improve the period requires photometry for this star over a longer period of time. Figure 3 shows the uvby photometry as a function of phase. HD 192678 is brightest in $u$ when the surface magnetic field strength is weakest. The amplitude in $u$ is $0.017 \mathrm{mag}$ and in $b$ is about $0.010 \mathrm{mag}$ while this star is essentially constant in $v$ and $y$. The light curves for $u$ and $b$ are shifted by about 0.15 in phase with $u$ reaching its maximum before $b$. This behavior is consistent with the need for a complex magnetic model such as that of Wade et al. (1996).

\section{HR 8216}

Adelman et al. (1994) presented differential uvby photometry of the mCP ultra-sharp lined star HR 8216 (= HD 204411) obtained between 1990 and 1994. The data for the three observing seasons with many observations showed that this star was constant and values in the literature indicate that this has been the case for many additional years. Its constancy has been confirmed also by Hipparcos photometry (ESA 1997). Any evidence of variability can lead to an estimate of its rotational period. Table 5 summarizes the FCAPT photometry. For three of the eight observing seasons, there are only a few observations and differences in $c h-c$ values between these and other years are probably due to their poorer statistics. The 1996-97 and 1997-98 seasons have sufficient observations to clearly show that HR 8216 was constant (Table 6 ). The telescope being moved just before the start of observing in the fall of 1996 and the order $0.01 \mathrm{mag}$ changes in $c h-c$ values seen between the last two and first 6 observing seasons might simply reflect small errors in the extinction. The offset seen in the $c h-c$ values of $b$ is currently unexplained. Comparison of the $v-c$ values for
1991-94 vs. 1996-97 show small offsets in $u, v, b$, and $y$, respectively of $0.004,0.000,0.007$, and $0.004 \mathrm{mag}$. Although these differences are suggestive of possible long term variability, observations in additional years are needed for confirmation.

Acknowledgements. This work was supported in part by NSF grants AST-9115114 and 9528506 and in part by grants from The Citadel Development Foundation. We appreciate the continuing efforts of Louis J. Boyd, Robert J., Dukes Jr., and George P. McCook to keep the FCAPT operating properly.

\section{References}

Abt H.A., Morrell N.I., 1995, ApJS 99, 135

Adelman S.J., 1998, Baltic Astron. 7, 427

Adelman S.J., Brunhouse E.F., 1998, PASP 110, 1304

Adelman S.J., Brown B.H., Caliskan H., Reese D.F., Adelman C.J., 1994, A\&AS 106, 333

Borra E.F., 1981, ApJ 249, L39

Burke E.W., Barr T.H., 1981, PASP 93, 344

ESA, 1997, The Hipparcos and Tycho Catalogs, SP-1200

Hoffleit D., 1982, The Bright Star Catalogue, 4th edition. Yale University Observatory, New Haven, CT

Hoffleit D., Saladyga M., Wlasuk P., 1983, A Supplement to the Bright Star Catalogue. Yale University Observatory, New Haven, CT

Horne J.H., Baliunas S.L., 1986, ApJ 302, 757

Leroy J.L., 1995, A\&AS 114, 79

Mathys G., Lanz T., 1992, A\&A 256, 169

Michaud G., Proffitt C.R., in ASP Conf. Proc. 44, Peculiar Versus Normal Phenomena in A-Type and Related Stars, Dworetsky M.M., Castelli F. \& Faraggiana R. (eds.), ASP, San Francisco, p. 439

North P., 1984, A\&AS 55, 259

Roberts D.H., Lehar J., Dreher J.W., 1987, AJ 93, 968

Scargle J.D., 1982, ApJ 263, 835

Stepien K., 1968, ApJ 154, 945

Wade G.A., Elkin V.G., Landstreet J.D., et al., 1996, A\&A 313, 209

Winzer J.E., 1974, Ph. D. Dissertation, University of Toronto 